\title{
PENINGKATAN PEMAHAMAN MAKNA TEMBANG PANGKUR DENGAN PENERAPAN MEDIA VIDEO PEMBELAJARAN PADA PESERTA DIDIK KELAS $X$ SMA NEGERI 1 CANDIROTO KABUPATEN TEMANGGUNG
}

\author{
LINA WAHYU SETYA UTAMI \\ SMA Negeri 1 Candiroto Kabupaten Temanggung Jawa Tengah \\ Email : linawahyu219@gmail.com
}

\begin{abstract}
ABSTRAK
Penelitian ini bertujuan untuk mendeskripsikan mengenai penerapan video pembelajaran untuk meningkatkan pemahaman peserta didik terhadap makna Tembang Pangkur. Fitur yang di teliti fokusnya adalah hasil belajar peserta didik dalam menerapkan bahan ajar berupa video sebagai media pembelajaran Tembang Macapat Pangkur. Dalam pembelajaran diperlukan evaluasi untuk mengukur tingkat keberhasilan seorang pengajar dalam menyampaikan materi khususnya tembang macapat, yang semula pembelajaran KD. Menelaah Teks Tembang Pangkur dilakukan tidak menggunakan media ajar berupa video, maka untuk meningkatkan pemahaman peserta didik dalam memaknai Tembang Pangkur dilakukan dengan menerapkan bahan ajar berupa video pembelajaran. Peningkatan pemahaman terhadap makna Tembang Pangkur, dapat dilihat dari hasil belajar peserta didik setelah menerapkan video pembelajaran. Dari 38 peserta didik kelas X SMA Negeri 1 Candiroto Kabupaten Temanggung Semester Ganjil Tahun Pelajaran 2021/2022 yang menjadi obyek penelitian dengan uji tes soal mengalami peningkatan hasil belajar peserta didik yang semula presentase ketuntasan 52,63\% sebelum menerapkan video pembelajaran, berdasarkan penelitian observer setelah menerapkan video pembelajaran mencapai ketuntasan $84,21 \%$.
\end{abstract}

Kata Kunci : Tembang Pangkur, Video Pembelajaran

\section{PENDAHULUAN}

Materi tembang macapat dalam mata pelajaran Bahasa Jawa di kelas X tetap harus diajarkan walaupun dalam kondisi pandemi Covid-19, peserta didik dituntut dapat memahami makna dari tembang macapat tersebut. Macapat berasal dari kata maca sipat, atau dalam bahasa Indonesia berarti "membaca sifat". Rangkaian sastra yang di bubuhkan dalam bentuk tembang macapat bisa diartikan sebagai unsur yang mengkiaskan fase-fase kehidupan manusia (Kurniawan, 2017). Dapat disimpulkan bahwa setiap tembang macapat menggambarkan proses perkembangan manusia sejak lahir sampai meninggal dunia.

Minimnya minat peserta didik terhadap materi tembang macapat membuat penulis mempertimbangkan penggunaan media pembelajaran yang tepat untuk memotivsi peserta didik agar tertarik dengan pembelajaran tembang macapat khususnya dalam memahami makna tembang agar bisa dijadikan tauladan dalam hal pendidikan budi pekerti. Beberapa kendala yang dihadapi oleh pengajar dalam menyampaikan materi tembang macapat adalah selain penggunaan Bahasa Jawa kuno yang asing terdengar oleh peserta didik juga penggunaan media pembelajaran yang dirasa kurang menarik.

Pemilihan video sebagai media pembelajaran tembang macapat di SMA Negeri 1 Candiroto dapat meningkatkan kompetensi dalam memaknai tembang macapat karena media video menggabungkan lebih dari satu media, mencakup visual, audio, audio-visual dapat menjadi alternatif pilihan dalam penggunaan media pembelajaran, sebab selain lebih variatif dalam tampilannya, juga menunjang dari segi modalitas belajar peserta didik serta lebih fleksible karena tidak terbatas ruang dan waktu. Video merupakan media audio visual yang sangat menarik dan memudahkan peserta didik dalam memahami esensi makna dari sebuah tembang. Melalui tayangan video cerita pendek durasi 13.26 menit, peserta didik mampu memahami filosofi tembang macapat karena diceritakan perjalanan hidup manusia sejak lahir hingga mati. 
Sri Anitah (2008) menyatakan bahwa media berasal dari bahasa latin yang merupakan bentuk jamak dari kata medium, yang berarti sesuatu yang terletak di tengah dapat diartikan sebagai perantara atau media pembelajaran maka tugas guru dalam menyampaikan bahanbahan pembelajaran akan lebih mudah sehingga tujuan pembelajaran akan tercapai. Kehadiran media pembelajaran yang dapat memberikan hasil pembelajaran yang berkualitas merupakan salah satu fungsi media pembelajaran. Proses pembelajaran tembang macapat tidak akan mencapai kualitas yang maksimal jika tidak menggunakan media pembelajaran.

Menurut Mahnun (2012) mengatakan bahwa pemilihan media hendaknya memperhatikan beberapa prinsip, yaitu: (1) kejelasan maksud dan tujuan pemilihan media, apakah untuk keperluan hiburan, informasi umum, pembelajaran dan sebagainya; (2) familiaritas media, yang melibatkan pengetahuan akan sifat dan ciri-ciri media yang akan dipilih; dan (3) sejumlah media dapat diperbandingkan karena adanya beberapa pilihan yang kiranya lebih sesuai dengan tujuan pengajaran. Video pembelajaran adalah salah satu media pembelajaran yang memenuhi ketiga prinsip yang dikemukakan Raharjo tersebut. Video merupakan media audiovisual. Menurut Setyosari dan Sihkabuden (2005), media audiovisual mempunyai kemampuan yang lebih, karena media mencakup indera pendengaran dan indera penglihatan.

Menurut Arsyad (2009) belajar dengan menggunakan indra ganda, akan memberikan keuntungan bagi peserta didik karena sesuai dengan konsep dual coding hypothesis (hipotesis koding ganda) dari Paivio yang mengatakan bahwa ada dua system ingatan manusia, satu untuk mengolah simbol-simbol verbal kemudian menyimpannya dalam bentuk proposisi image, dan yang lainnya untuk mengolah image nonverbal yang kemudian disimpan dalam bentuk proposisi verbal. Dari sini dapat disimpulkan bahwa video sebagai media dalam pembelajaran yang menggunakan alat indra penglihatan dan pendengaran akan memberikan keuntungan untuk peserta didik tersebut dikarenakan pembelajaran sesuai dengan konsep pembelajaran dual coding hypothesis.

Hal ini juga selaras dengan beragamnya modalitas belajar peserta didik. Bobbi De Porter dan Hernacki (dalam Musfiqon 2012 ), modalitas belajar terdiri dari : (1) visual, yaitu belajar dengan cara melihat, (2) auditorial, yaitu belajar dengan cara mendengar, dan (3) kinestetik, belajar dengan cara bergerak, bekerja, dan menyentuh. Maka dari itu guru harus dapat memfasilitasi gaya belajar peserta didik yang beraneka ragam seperti gaya belajar visual, auditori dan kinestetik. Guru harus mahir dalam menggunakan beberapa media pembelajaran tidak cukup satu media saja, misalnya dalam hal ini hanya melibatkan indera visual saja, dikhawatirkan materi tidak dapat diterima secara optimal oleh peserta didik karena faktor perbedaan modalitas belajar setiap peserta didik.

Menurut Darsono (2016) bahwasannya macapat diartikan "macapat lagu", yaitu bacaan keempat. Tembang macapat berisi ajaran-ajaran luhur yang diambil dari pengalaman sejarah maupun nilai-nilai kehidupan yang terdapat dalam berbagai cerita pewayangan sebagai pralambang manusia, sehingga apabila dilagukan dapat diibaratkan menaburkan bunga yang harum, menyenangkan, menggembirakan, menyentuh hati dan enak didengar. Bagi para pendengarnya akan merasuk dalam kalbu sekaligus dijadikan sebagai pedoman hidup yang menuntun kearah kesempurnaan. Ketidakmampuan peserta didik di SMA Negeri 1 Candiroto Kabupaten Temanggung dalam menafsirkan isi tembang dan sulitnya memahami makna tembang Pangkur, sehingga peserta didik tidak bisa secara maksimal meneladani nilai-nilai yang terkandung dalam tembang macapat Pangkur, selain itu juga kurangnya motivasi peserta didik dalam mempelajari tembang macapat sebagai mata pelajaran muatan lokal Bahasa Jawa dan dirasa kurang menarik karena penggunaan bahasa Jawa kuno yang tidak dimengerti oleh peserta didik menjadikan pertimbangan penulis dalam pemilihan bahan ajar yang tepat. Sebelumnya pembelajaran dilakukan secara konvensional yaitu dengan metode ceramah maka video pembelajaran dipandang menarik karena memanfaatkan tehnologi dalam menyampaikan materi tembang macapat. 
Menurut maknanya, Tembang Pangkur itu menggambarkan waktu ketika sudah melampaui usia, sudah saatnya meninggalkan urusan dunia. Wataknya semangat, satria artinya serius dalam hal menjauhkan hawa nafsu yang bersifat keduniawian, agar tidak mengganggu hidup. Hatinya sudah mantap, bersih, tidak tergesa-gesa dan mengutamakan ibadah, mendekatkan diri kepada Tuhan Yang Maha Esa. Pangkur menggambarkan orang yang sudah tua. Kata "pangkur" berasal dari kata "mungkur", menjauhi dari hal-hal yang bersifat tidak baik.

\section{METODE PELAKSANAAN}

Penelitian ini menggunakan metode penelitian Best Practice .Tujuannya adalah untuk melaporkan pengalaman mengajar dan hasil belajar peserta didik dalam menerapkan media video pembelajaran dalam memaknai tembang macapat yaitu Tembang Pangkur. Subyek dari penelitian ini adalah peserta didik kelas X Semester Ganjil Tahun Pelajaran 2021 /2022 SMA Negeri 1 Candiroto, kabupaten Temanggung sejumlah 38 peserta didik. Obyek yang dilaporkan adalah hasil belajar peserta didik dengan KD. Menelaah teks Serat Wedhatama Pupuh Pangkur.

Tahapan pengambilan data dalam penelitian kualitatif ini adalah : Perencanaan, Pratindakan, Pelaksanaan, Pengamatan dan Refleksi.

1. Perencanaan : Menyiapkan soal menggunakan apikasi Google Form.

2. Pratindakan : Melaksanakan penilaian pretest

3. Pelaksanaan : Melaksanakan pembelajaran tembang menggunakan bahan ajar video

4. Pengamatan : Melaksanakan penilaian postest dan membandingkan hasil dengan pretest

5. Refleksi : Hasil belajar peserta didik akan dijadikan bahan refleksi untuk menentukan langkah-langkah pembelajaran berikutnya.

Untuk mengetahui peningkatan pemahamana peserta didik terhadap makna Tembang Pangkur, dilakukan pengambilan data sebanyak dua kali dengan dua perlakuan yang berbeda yang pertama penilaian dilakukan sebelum peserta didik menyimak video, yang kedua penilaian dilakukan setelah peserta didik menyimak video. Pengolahan data berdasarkan input nilai dari hasil pelaksanaan pretest dan postest.

\section{HASIL DAN PEMBAHASAN}

\section{Hasil}

Proses pengambilan data dengan menggunakan instrument test. Soal test disusun menggunakan aplikasi Google Form sejumlah 20 butir pertanyaan pilihan ganda, yang terdiri dari lima option jawaban, sedangkan indikator soalnya yaitu penjabaran dari KD Menelaah teks Serat Wedhatama Pupuh Pangkur. Pedoman penskoran 5 point untuk jawaban benar dan 0 untuk jawaban salah.

Tabel 1. Hasil belajar peserta didik sebelum menggunakan media video

\begin{tabular}{|c|c|l|l|c|c|}
\hline No & SKOR & NAMA & Jenis kelamin & KELAS & No.Absen \\
\hline 1 & $50 / 100$ & Alfin & laki-laki & X-4 & 4 \\
\hline 2 & $85 / 100$ & Andira & perempuan & X-4 & 6 \\
\hline 3 & $70 / 100$ & Anita & perempuan & X-4 & 7 \\
\hline 4 & $85 / 100$ & Choirul & laki-laki & X-4 & 11 \\
\hline 5 & $15 / 100$ & Diva & perempuan & X-4 & 15 \\
\hline 6 & $20 / 100$ & Fridhea & perempuan & X-4 & 18 \\
\hline 7 & $40 / 100$ & Ilman & laki-laki & X-4 & 19 \\
\hline 8 & $45 / 100$ & Lutviana & perempuan & X-4 & 21 \\
\hline 9 & $75 / 100$ & Bila & perempuan & X-4 & 23 \\
\hline 10 & $95 / 100$ & Naila & perempuan & X-4 & 24 \\
\hline 11 & $75 / 100$ & Naura & perempuan & X-4 & 25 \\
\hline 12 & $65 / 100$ & Novi & perempuan & X-4 & 26 \\
\hline 13 & $90 / 100$ & Ria & perempuan & X-4 & 30 \\
\hline
\end{tabular}


SECONDARY : Jurnal Inovasi Pendidikan Menengah

Vol 1. No 4. Oktober 2021 P-ISSN : 2774-8022, e-ISSN : 2774-5791

\begin{tabular}{|c|c|l|l|c|c|}
\hline 14 & $70 / 100$ & Rini & perempuan & $\mathrm{X}-4$ & 31 \\
\hline 16 & $65 / 100$ & Vina & perempuan & $\mathrm{X}-4$ & 35 \\
\hline 15 & $65 / 100$ & Abi & laki-laki & $\mathrm{X}-3$ & 1 \\
\hline 17 & $85 / 100$ & Aisha & perempuan & $\mathrm{X}-3$ & 3 \\
\hline 18 & $15 / 100$ & Apria & laki-laki & $\mathrm{X}-3$ & 5 \\
\hline 19 & $70 / 100$ & Asti & perempuan & $\mathrm{X}-3$ & 7 \\
\hline 20 & $85 / 100$ & Cahya & perempuan & $\mathrm{X}-3$ & 9 \\
\hline 21 & $55 / 100$ & Eliza & perempuan & $\mathrm{X}-3$ & 13 \\
\hline 22 & $55 / 100$ & Farid & laki-laki & $\mathrm{X}-3$ & 15 \\
\hline 23 & $60 / 100$ & Ferly & laki-laki & $\mathrm{X}-3$ & 17 \\
\hline 24 & $85 / 100$ & Nova & perempuan & $\mathrm{X}-3$ & 23 \\
\hline 25 & $75 / 100$ & Wahyu & perempuan & $\mathrm{X}-3$ & 29 \\
\hline 26 & $90 / 100$ & Yeni & perempuan & $\mathrm{X}-3$ & 31 \\
\hline 27 & $75 / 100$ & Yuyun & perempuan & $\mathrm{X}-3$ & 33 \\
\hline 28 & $65 / 100$ & Zahra & perempuan & $\mathrm{X}-3$ & 35 \\
\hline 29 & $90 / 100$ & Zulfatun & perempuan & $\mathrm{X}-3$ & 36 \\
\hline 30 & $75 / 100$ & Alim & laki-laki & $\mathrm{X}-2$ & 5 \\
\hline 31 & $55 / 100$ & Anggun & perempuan & $\mathrm{X}-2$ & 7 \\
\hline 32 & $80 / 100$ & Janatun & perempuan & $\mathrm{X}-2$ & 19 \\
\hline 33 & $80 / 100$ & Nabila & perempuan & $\mathrm{X}-2$ & 23 \\
\hline 34 & $70 / 100$ & Nanda & laki-laki & $\mathrm{X}-2$ & 24 \\
\hline 35 & $40 / 100$ & Niken & perempuan & $\mathrm{X}-2$ & 27 \\
\hline 36 & $65 / 100$ & Riska & perempuan & $\mathrm{X}-2$ & 32 \\
\hline 37 & $90 / 100$ & Aulia & perempuan & $\mathrm{X}-1$ & 5 \\
\hline 38 & $65 / 100$ & Ratna & perempuan & $\mathrm{X}-1$ & 23 \\
\hline & & & & & \\
\hline
\end{tabular}

Tabel 2. Hasil belajar peserta didik sesudah menggunakan media video.

\begin{tabular}{|c|c|l|l|c|c|}
\hline No & Skor & Nama & Jenin kelamin & Kelas & No.Absen \\
\hline 1 & $60 / 100$ & Alfin & laki-laki & X-4 & 4 \\
\hline 2 & $95 / 100$ & Andira & perempuan & X-4 & 6 \\
\hline 3 & $90 / 100$ & Anita & perempuan & X-4 & 7 \\
\hline 4 & $95 / 100$ & Choirul & laki-laki & X-4 & 11 \\
\hline 5 & $35 / 100$ & Diva & perempuan & X-4 & 15 \\
\hline 6 & $45 / 100$ & Fridhea & perempuan & X-4 & 18 \\
\hline 7 & $70 / 100$ & Ilman & laki-laki & X-4 & 19 \\
\hline 8 & $60 / 100$ & Lutviana & perempuan & X-4 & 21 \\
\hline 9 & $80 / 100$ & Bila & perempuan & X-4 & 23 \\
\hline 10 & $95 / 100$ & Naila & perempuan & X-4 & 24 \\
\hline 11 & $85 / 100$ & Naura & perempuan & X-4 & 25 \\
\hline 12 & $70 / 100$ & Novi & perempuan & X-4 & 26 \\
\hline 13 & $95 / 100$ & Ria & perempuan & X-4 & 30 \\
\hline 14 & $80 / 100$ & Rini & perempuan & X-4 & 31 \\
\hline 15 & $90 / 100$ & Vina & perempuan & X-4 & 35 \\
\hline 16 & $90 / 100$ & Abi & laki-laki & X-3 & 1 \\
\hline
\end{tabular}


SECONDARY : Jurnal Inovasi Pendidikan Menengah

Vol 1. No 4. Oktober 2021 P-ISSN : 2774-8022, e-ISSN : 2774-5791

\begin{tabular}{|c|c|c|c|c|c|}
\hline 17 & $95 / 100$ & Aisha & perempuan & X-3 & 3 \\
\hline 18 & $35 / 100$ & Apria & laki-laki & $X-3$ & 5 \\
\hline 19 & $95 / 100$ & Asti & perempuan & $X-3$ & 7 \\
\hline 20 & $90 / 100$ & Cahya & perempuan & $X-3$ & 9 \\
\hline 21 & $80 / 100$ & Eliza & perempuan & $X-3$ & 13 \\
\hline 22 & $80 / 100$ & Farid & laki-laki & $X-3$ & 15 \\
\hline 23 & $75 / 100$ & Ferly & laki-laki & $X-3$ & 17 \\
\hline 24 & $95 / 100$ & Nova & perempuan & $X-3$ & 23 \\
\hline 25 & $90 / 100$ & Wahyu & perempuan & $X-3$ & 29 \\
\hline 26 & $95 / 100$ & Yeni & perempuan & $X-3$ & 31 \\
\hline 27 & $90 / 100$ & Yuyun & perempuan & $X-3$ & 33 \\
\hline 28 & $80 / 100$ & Zahra & perempuan & $X-3$ & 35 \\
\hline 29 & $95 / 100$ & Zulfatun & perempuan & $X-3$ & 36 \\
\hline 30 & $80 / 100$ & Alim & laki-laki & $X-2$ & 5 \\
\hline 31 & $75 / 100$ & Anggun & perempuan & $X-2$ & 7 \\
\hline 32 & $85 / 100$ & Janatun & perempuan & $\mathrm{X}-2$ & 19 \\
\hline 33 & $85 / 100$ & Nabila & perempuan & $X-2$ & 23 \\
\hline 34 & $85 / 100$ & Nanda & laki-laki & $X-2$ & 24 \\
\hline 35 & $90 / 100$ & Niken & perempuan & $X-2$ & 27 \\
\hline 36 & $55 / 100$ & Riska & perempuan & $X-2$ & 32 \\
\hline 37 & $95 / 100$ & Aulia & perempuan & $X-1$ & 5 \\
\hline 38 & $90 / 100$ & Ratna & perempuan & $X-1$ & 23 \\
\hline
\end{tabular}

Analisis hasil pengamatan dapat dilihat dari diagram batang berikut ini :

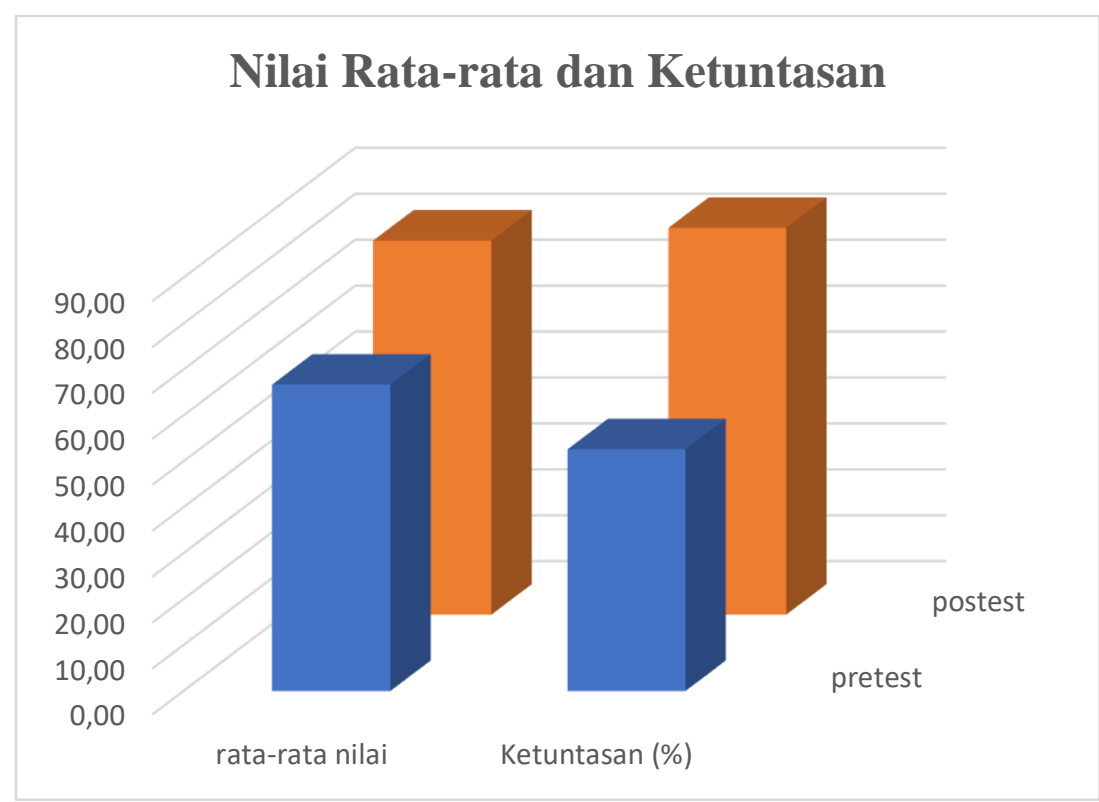

Gambar 1. Nilai Rata-rata dan Ketuntasan

\section{Pembahasan}

Berdasarkan diagram diatas dapat ditemukan hasil sebagai berikut : 
1. Dari 38 jumlah peserta didik yang observer teliti, sebelum diterapkan pemberian materi menggunakan media video pembelajaran, terdapat 20 peserta didik yang berhasil mendapatkan nilai diatas $\mathrm{kkm}$ dan 18 peserta didik dibawah $\mathrm{kkm}$ dengan persentase masing masing $52,63 \%$ dan $47,36 \%$.

2. Dari 38 jumlah peserta didik yang observer teliti, setelah diterapkan pemberian materi menggunakan media video pembelajaran, terdapat 32 peserta didik yang berhasil mendapatkan nilai diatas $\mathrm{kkm}$, dan 6 peserta didik dibawah $\mathrm{kkm}$ dengan persentase masing masing $84,21 \%$ dan $15,78 \%$.

Hasil penelitian tersebut ditemukan adanya peningkatan $31.58 \%$ ketuntasan hasil belajar peserta didik terhadap pemahaman makna tembang macapat setelah diterapkan media video pembelajaran di Kelas X Semester Ganjil Tahun Pelajaran 2021/2022. Hal ini diperkuat oleh hasil penelitian Rizqi, Amir dan Daryono (2015) yang menyatakan dengan menggunaan media video interaktif dapat meningkatkan kemampuan mengapresiasi tembang macapat pada siswa kelas IV SD Negeri Karangasem III No. 181 Surakarta tahun pelajaran 2014/2015. Hasil peningkatan nilai kemampuan mengapresiasi tembang macapat terjadi secara bertahap. Peningkatan dapat dilihat dari nilai dan ketuntasan klasikal sebelum dan setelah dilakukan tindakan, yaitu pada siklus I dan siklus II.

Penelitian lain dilakukan oleh Elizabeth (dalam Raharjayanti dan Widagdo ,2021) dari penelitian ini dapat disimpulkan bahwa hasil belajar siswa kelas X SMA Negeri 6 Medan Tahun Pembelajaran 2013/2014 dengan menggunakan video pembelajaran tergolong baik dengan nilai rata-rata 80,8 .

Tehnik pengambilan data dengan uji tes soal, data berupa nilai hasil dari jawaban peserta didik. Obyek penelitian adalah peserta didik kelas X SMA Negeri 1 Candiroto Kabupaten Temanggung Semester Ganjil Tahun Pelajaran 2021/2022 sejumlah 38 peserta didik, yang telah mengirimkan jawaban secara tepat waktu dengan dua perlakuan, yang pertama pelaksanaan tes sebelum menyimak video dan yang kedua sesudah menyimak video. Ketuntasan belajar dengan KKM 70, peserta didik dianggap berhasil dalam proses pembelajaran jika nilai minimum 70 . Dari hasil perhitungan ketuntasan pembelajaran daring dalam memaknai tembang macapat, sebelum menggunakan media video cerita pendek ditemukan ada 20 peserta didik yang tuntas dan 18 peserta didik yang tidak tuntas, sedangkan setelah pemanfaatan video cerita pendek terdapat 32 peserta didik yang tuntas dan 6 peserta didik yang tidak tuntas.

\section{KESIMPULAN}

Berdasarkan uraian di atas dapat ditarik kesimpulan sebagai berikut:

1. Kemampuan peserta didik dalam memaknai Tembang Pangkur sebelum menerapkan video pembelajaran dan berdasarkan observasi sebanyak 20 peserta didik dengan persentase $52,63 \%$, sedangkan peserta didik yang tidak mencapai ketuntasan sebanyak 18 peserta didik dengan persentase $47,36 \%$. Sehingga dapat diketahui bahwa tingkat kemampuan peserta didik dalam memaknai tembang masih rendah. Hal ini menunjukan bahwa peserta didik belum mampu memahami dengan baik makna dari Tembang Pangkur. Maka dari itu dibutuhkan media video pembelajaran.

2. Kemampuan peserta didik dalam memaknai Tembang Pangkur setelah menerapkan video pembelajaran dan berdasarkan observasi sebanyak 32 peserta didik dengan persentase $84,21 \%$ sedangkan peserta didik yang tidak tuntas sebanyak 6 peserta didik dengan persentase $15,78 \%$. Hal ini menunjukan bahwa kemampuan memahami makna Tembang Pangkur peserta didik mengalami peningkatan setelah menerapkan media video pembelajaran .

3. Selama proses pembelajaran menggunakan media berupa, tampak bahwa respon belajar peserta didik sangat tinggi dan baik. Hal ini dapat dilihat dari hasil tes sebelum menerapkan video dan sesudah menerapkan video pembelajaran, serta dapat dibuktikan perbedaannya dengan perolehan selisih nilai rata-rata 14,74 dan peningkatan $31.58 \%$. 
4. Pemanfaatan media video dianggep lebih efektif dalam pembelajaran karena menampung modalitas peserta didik baik secara visual maupun auditorial.

\section{DAFTAR PUSTAKA}

Anitah, Sri. (2008). Media Pembelajaran. Surakarta :Panitia Sertifikasi Guru Rayon 13 Surakarta

Arsyad, Azhar. 2002. Media Pembelajaran. Jakarta : PT Rajagrafindo Persada.

Darsono (2016). Beberapa Pandangan tentang Tembang Macapat : Jurnal Pengetahuan, Pemikiran, dan Kajian tentang Bunyi, Volume 16, No.1.

Kurniawan (2017). Makna Tembang Macapat sebagai Ide Penciptaan Karya Seni Lukis, Tugas Akhir Karya Seni : Universtas Negeri Yogyakarta.

Mahnun, Nunu. (2012). Media Pembelajaran. Jurnal Pemikiran Islam, Vol. 37 No. 1.

Musfiqon. 2012. Pengembangan Media Belajar Dan Sumber Belajar. Jakarta : Prestasi Pustakakarya

Raharjayanti dan Widagdo (2021). Keefektifan Media Video Pembelajaran dari Youtube terhadap Keterampilan Menyimak dan Melagukan Tembang Macapat Kelas IV : Joyful Learning Journal 10 (1).

Rizqi, Amir dan Daryanto (2015) . Peningkatan Kemampuan Mengapresiasi Tembang Macapat Melalui Media Video Interaktif : jurnal.fkip.uns.ac.id,Vol.3 No.9

Setyosari, P dan Sihkabuden. (2005). Media Pembelajaran. Malang: Elang Press. 